\title{
Design de interface sistematizado como processo de produto
}

Interface design systematized as product process

Jaire Ederson Passos, Tânia Luisa K. da Silva

design, interação, interface, metodologia

\begin{abstract}
Este artigo relata a proposição de metodologia para o design de interface sistematizado como processo de desenvolvimento de produto, considerando princípios de design de interação e aspectos de usabilidade e ergonomia. A composição de metodologia que agrega ferramentas do processo de produto, como o desdobramento da função qualidade, a princípios do design gráfico e do design de interação objetiva fornecer forte embasamento científico para as usualmente aplicadas heurísticas do design de interface. Nesse sentido, a pesquisa recorre ainda a referências de engenharia de software e de arquitetura da informação, além de princípios de composição visual. Para validação do processo, desenvolveu-se a interface do ambiente digital HyperCAL online (módulo do professor), um projeto do Grupo de Pesquisa Virtual Design, da Universidade Federal do Rio Grande do Sul (UFRGS), desenvolvido para apoiar o ensino presencial de Design e Expressão Gráfica nos cursos de graduação da universidade.
\end{abstract}

design, interaction, interface, method

This article reports the proposition methodology for systematic interface design as product development process, considering principles of interaction design and aspects of usability and ergonomics. The composition of methodology that combines tools of the process of product, such asthe quality function deployment, to principles of graphic design and interaction design aims to provide a strong scientific basis for the commonly applied heuristics of interface design. In this sense, the research also uses references to software engineering and information architecture, as well as principles of visual composition. To validate the process, has been developed the interface of digital environment HyperCAL online (module for academics), a project of the Virtual Design Research Group, from Universidade Federal do Rio Grande do Sul (UFRGS), developed to support classroom teaching of Design and Graphic Expression in the undergraduate courses of the university.

\section{Introdução}

Este artigo apresenta o desenvolvimento de metodologia específica para design de interface de ambiente virtual centrado no usuário. A metodologia Hypercal, como foi denominada, é sistematizada como processo de desenvolvimento de produto, com princípios de Design de Interação e considera aspectos de usabilidade e ergonomia. Objetiva-se, assim, favorecer o trabalho do usuário, permitindo a apropriação do conteúdo e a execução das tarefas através das funcionalidades do sistema. Este artigo apresenta os desdobramentos da metodologia Hypercal, explicitando suas fases e etapas de processo, desenvolvidas para o projeto de interface do sistema HyperCAL online, módulo de gerenciamento de produção flexível de objetos educacionais.

O HyperCAL online, um projeto do Grupo de Pesquisa Virtual Design, da Universidade Federal do Rio Grande do Sul (UFRGS) é construido com base na pesquisa de Silva (2005) e consiste em um ambiente digital para apoio ao ensino presencial de Design e Expressão Gráfica. Desde sua primeira versão, em 1999, esse sistema vem sendo utilizado em diversas disciplinas dos cursos de Engenharia, e mais recentemente, também nos cursos de Design Visual e de Design de Produto, preponderantemente na UFRGS.

Para consecução do trabalho foram investigados: os Elementos da Experiência do Usuário (Garret, 2003); os conceitos do Design de Interação (Preece, Rogers e Sharp, 2005); as técnicas da Engenharia de Software (Pressman, 2002); e ferramentas do Processo de Desenvolvimento de Produto (Baxter, 1998). A combinação desses estudos deu origem à metodologia proposta nesta pesquisa. Consideram-se, ainda, heurísticas e pesquisas de usabilidade como as de Nielsen (2008), Norman (2002) e Kalbach (2009). Destaca-se que essa metodologia integra a técnica do desdobramento da função qualidade a estudos usualmente adotados para o design de interface 
gráfica. O próximo item se destina à descrição dos principais estudos que deram base para a pesquisa e o desenvolvimento da metodologia Hypercal.

\section{Metodologias de projeto}

O Design de Interação (Preece, Rogers e Sharp, 2005) é considerado nesta pesquisa por ressaltar o foco no usuário e estabelecer metas para garantir-lhe uma experiência satisfatória quando do contato com uma interface. Para isso, recorre a heurísticas e pesquisas de usabilidade como as de Nielsen (2005) e Norman (2002). A Engenharia de Software (Pressman, 2002), com a Iweb, por sua vez, contribui com embasamento teórico consistente e com um processo de desenvolvimento de interface em etapas detalhadas, descrevendo com maior precisão os passos necessários até se alcançar o produto final.

Já a abordagem de Garrett (2003) interessa ainda mais a este trabalho por dois motivos específicos, que são os seguintes: dá ênfase especial ao design visual dos elementos gráficos que farão parte do leiaute e prevê solução para quando a interface é usada como software remoto na internet. A Iweb já tratava de interfaces para aplicativos, porém não estabelecia uma diferenciação explícita entre metodologias para interface voltada à tarefa e interface para hipertexto. Os Elementos da Experiência do Usuário, no entanto, definem com clareza as etapas próprias a cada processo e trazem uma proposta adequada ao projeto do HyperCAL online.

Ainda, a questão visual é tratada por Pressman (2002) como principalmente estética. Garrett (2003), todavia, argumenta que o design visual é mais que estética, pois envolve também funcionalidade, legibilidade e estratégia de posicionamento de marca. O projeto gráfico é, nesse caso, tratado com maior relevância e desdobrado em maiores detalhes.

Além de apoiar-se nas etapas dos Elementos da Experiência do Usuário, para garantir que o design de interface seja centrado no usuário e para que a qualidade esteja presente em todas as etapas do projeto, este trabalho é sistematizado como Processo de Desenvolvimento de Produto (Baxter, 1998). A metodologia de Garrett (2003) propõe, em sua primeira etapa, a pesquisa de interesses do usuário e o estabelecimento de objetivos. O Processo de Desenvolvimento de Produto, entretanto, dá conta de sistematizar a transformação das necessidades do usuário em metas e estabelecer ferramentas para que o foco nessas metas seja mantido ao longo do projeto.

O foco no usuário é fator central no design de uma interface, e para tornar as necessidades do usuário em requisitos técnicos, mantendo-se a qualidade no processo de produção, são usadas ferramentas profissionais para o desenvolvimento de produto, como o desdobramento da função qualidade (QFD). A matriz de correlação, ou casa de qualidade, é utilizada com a intenção de obterem-se informações úteis para o controle de qualidade, precisas e fiéis às necessidades do consumidor identificadas (Baxter, 1998).

A partir desses estudos, propõe-se uma metodologia que não se apropria, simplesmente, da abordagem de algum autor, mas que é construída com base em diversos autores e de acordo com o contexto do problema em questão. Considera-se, portanto, que a combinação dos processos apresentados em cada uma das obras citadas resulta em uma metodologia que proporciona a construção de uma interface mais regida por constatações científicas e não somente por heurísticas. O Quadro 1 traz relatos dos aspectos mais relevantes de cada processo, sistematizados de forma a permitir a comparação.

\begin{tabular}{|l|l|}
\hline Quadro 1 \\
\hline \begin{tabular}{l|l|} 
Processo de Produto & Engenharia de Software \\
Baxter (1998) & Pressman (2001) \\
\hline Especificação do projeto & Formulação \\
- Conversão das necessidades do consumidor em & Identifica metas e objetivos; apresenta escopo \\
requisitos técnicos & resumido do projeto; define perfil do usuário \\
- Matriz de correlação & \\
- Análise dos concorrentes & Planejamento \\
- Fixação metas quantitativas & Avalia os riscos associados, custos, planejamento \\
- Priorização das metas & detalhado. \\
\hline
\end{tabular}
\end{tabular}


- Levantamento de aspectos relevantes não percebido pelos consumidores

- Pesquisa de informações internas e externas

- Especificação preliminar

- Revisão da especificação

- Versão final

Plano de desenvolvimento

- Projeto conceitual

- Princípios de projeto e idéias preliminares, princípios funcionais e de estilo, diferenciação da concorrência.

- Configuração do projeto

- Arquitetura do produto, formas e funções, definição das melhores opções (fase onde é construído o protótipo)

- Projeto detalhado

- Detalhamento do projeto para a produção.

- Cronograma e distribuição de tarefas

- Estabelecimento de etapas de desenvolvimento.

\section{Análise}

- Definição de equisitos técnicos

- Identificação do conteúdo

- Definição de requisitos de design

- Análise de conteúdo (textos, vídeos, gráficos, imagens e sons)

- Análise da interação

- Análise funcional

- Análise da configuração (descrição detalhada da estrutura que será usada pela WebApp, internet ou intranet)

\section{Engenharia}

- Desenho de conteúdo (produção do conteúdo)

- Produção

Desenho arquitetônico

Definição de templates

Desenho de navegação

Definição da semântica de navegação para diferentes usuários (sinalização).

\section{Desenho de interface}

- Desenho da interface

- Implementação

- Validação da interface

- Análise de usuários tarefas e entornos

Geração de páginas e testes

Teste no navegador

Avaliação do cliente

Design de Interação

Preece, Rogers e Sharp (2005)

Garrett (2003)

Estratégia inicial

- Definição de metas

- Levantamento de necessidades do usuário

- Objetivos do site de origem externa identificados por meio de pesquisa com o

\section{Requisitos}

Identificar necessidades e estabelecer requisitos

Design

Desenvolver designs que preencham os requisitos 


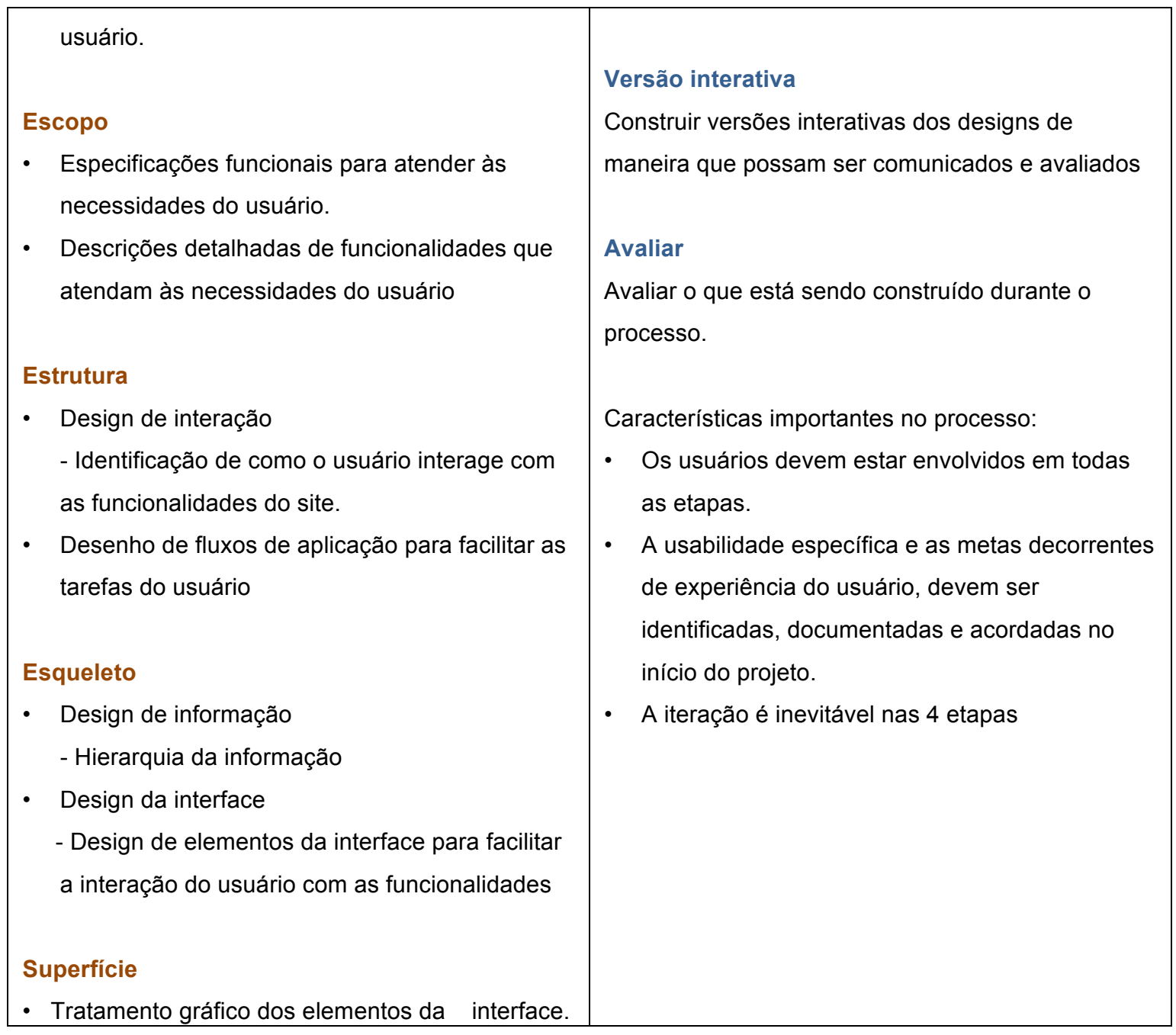

\section{Metodologia Hypercal}

A seguir, tem-se a descrição da Metodologia Hypercal, obedecendo aos seguintes passos: a) Percepção; b) Alvo; c) Configuração; d) Esboço; e) Refino. Essas fases são descritas em seus procedimentos específicos em um total de 25 etapas.

\section{Fase (a) Percepção:}

A fase percepção apresenta uma visão geral das questões envolvidas na situação inicial do problema. Diferentemente da primeira etapa de Garrett (2003), não busca-se por uma estratégia, mas apenas pela compreensão e pelo registro das definições gerais, como nas primeiras etapas da Engenharia de Web (Pressman, 2002). Para tanto, as etapas desenvolvidas constam de levantamento de informações; de identificação de objetivos, recursos e prazos; de definição de requisitos de usuário e de análises relativas ao assunto a ser tratado. Para compor essa fase inicial recorreu-se às quatro abordagens citadas anteriormente, a saber: Processo de Produto (Baxter, 1998), Engenharia de Software (Pressman, 2002), Experiência do Usuário (Garrett, 2003) e Design de Interação (Preece, Rogers e Sharp, 2005). Em cada uma delas, estão presentes etapas semelhantes às que serão apresentadas - mesmo que em algumas delas o nível de detalhamento seja menor.

O destaque para a fase percepção está na etapa de investigação de tendências, onde, com base no Processo de Produto, busca-se a diferenciação da concorrência. Para tanto, procede-se às análises diacrônica e sincrônica de temas relacionados. Ainda, a etapa de identificação de 
requisitos, mesmo estando presente nas quatro abordagens, é, aqui, focada também na proposta do Processo de Produto. Os itens a seguir apresentam cada uma das etapas dessa fase.

\section{Levantamento de informações}

O levantamento das informações trata-se do estudo dos temas relacionados e do agrupamento dos assuntos disponíveis e relevantes para a pesquisa. Para este trabalho, foram levantadas as informações documentadas em Silva (2005) e Mendes (2009).

\section{Identificação dos objetivos do projeto}

Com base em Powell, Jones e Cutts (1998) esta etapa inicial procura respostas diretas e sucintas para as perguntas seguintes: a) Qual a motivação principal para o aplicativo? B) Por que é necessário o aplicativo? C) Quem vai utilizar o aplicativo? Essas respostas são obtidas a partir do levantamento das informações, efetuado na primeira etapa da metodologia.

\section{Identificação dos recursos disponíveis}

É preciso conhecer a disponibilidade de recursos humanos e materiais (financeiros e tecnológicos) antes de dar prosseguimento ao projeto.

\section{Identificação dos prazos}

Os prazos de desenvolvimento e entrega final precisam ser conhecidos para a montagem do cronograma de trabalho.

\section{Análises denotativa e conotativa}

A etapa das análises ajuda a identificar a situação inicial do problema e a direcionar os passos a serem seguidos. As informações obtidas nessa fase enriquecem o projeto, dão base ao processo criativo e podem ajudar a identificar necessidades latentes. São propostas as análises denotativa e conotativa de conceitos relacionados ao tema, com base no Dicionário de informática e internet, de Sawaya (1999).

\section{Investigação de tendências}

A investigação das tendências é feita a partir das pesquisas diacrônica e sincrônica de temas relacionados com a pesquisa. A análise diacrônica olha para o passado e estuda a evolução dos acontecimentos em busca de referências que subsidiem a criação. A análise sincrônica olha para os lados e reúne pesquisas recentes que possam contribuir para o trabalho.

\section{Identificação dos requisitos do usuário}

Essa etapa é baseada no Processo de Produto (Baxter, 1998) e busca identificação e hierarquização dos requisitos do usuário. Para tanto, é feito levantamento inicial de requisitos e em seguida é construído um questionário para investigar diretamente com o usuário quais seus principais interesses. Nessa pesquisa, o levantamento e identificação dos requisitos do usuário foi feito através da pesquisa descrita em Mendes (2009), de entrevistas com usuários e de pesquisa em literatura específica da área de interface.

\section{Registro das informações}

É preciso que o material levantado seja devidamente organizado e registrado. Para tanto, a fase de registro das informações prevê a elaboração de relatório de pesquisa.

\section{Fase (b) Alvo}


A segunda fase da metodologia recebe o nome de alvo porque objetiva o detalhamento e refino das informações. Para tanto, apresenta investigações mais aprofundadas e específicas do que as realizadas na fase anterior.

As etapas principais da fase alvo estão embasadas no Processo de Produto (Baxter, 1998), com a definição dos requisitos de projeto e a casa de qualidade, propostas na investigação de oportunidades para inovação; a montagem de condicionantes e listagem de projetações (essa última também presente na Engenharia de Software e na Experiência do Usuário). Já a etapa de investigação da identidade visual é construída a partir da ênfase que a proposta da Experiência do Usuário (Garrett, 2003) dá ao assunto, enquanto a etapa de definição de tarefas e prazos é baseada no Planejamento Detalhado da Engenharia de Software (Pressman, 2002).

\section{Investigação de oportunidades para inovação}

A investigação de oportunidades para inovação envolve a análise de sistemas similares e o uso de ferramentas de Processo de Produto (Baxter, 1998). Inicialmente, usa-se a técnica do desdobramento da função qualidade (quality function deployment ou QFD) e aplica-se a casa de qualidade. Essa etapa prevê a contribuição de profissionais e pesquisadores da área do design de interface para o trabalho de transformação dos requisitos de usuário em requisitos de projeto.

Em seguida, a investigação de necessidades latentes do usuário e proposta de inovações é efetuada a partir da avaliação dos resultados do QFD e também através da análise de sistemas similares. Nesta pesquisa, os sistemas estudados foram o Google Docs e o Microsoft Word 2007.

\section{Investigação de identidade visual}

Essa etapa investiga o perfil de identidade visual que será empregado. Para tanto, é desenvolvido um questionário e aplicado com os responsáveis pelo projeto, procurando identificar suas expectativas quanto a imagem pretendida para a marca. Em seguida é construído um painel de diferencial semântico, que trata-se de um gráfico que permite a melhor visualização dos ideais conceituais e a priorização de qualidades desejáveis à interface.

\section{Montagem dos condicionantes}

A montagem dos condicionantes é uma técnica apresentada em Baxter (1998) para estimular a criatividade. O mapa do problema traz uma representação gráfica que auxilia na definição e permite visualização das fronteiras do problema, do espaço do problema, das soluções existentes e da meta do problema.

\section{Listagem de projetações}

A lista de projetações reúne as necessidades do usuário identificadas a partir das análises e traz a definição das metas e do conceito para o projeto. Trata-se de uma lista resumida e objetiva com itens para verificação.

\section{Definição de tarefas e prazos}

A fase alvo é encerrada com a difusão das informações levantadas para a equipe de projeto e a definição de tarefas, com estabelecimento de responsabilidades e prazos.

\section{Fase (c) Configuração}

A configuração é a primeira fase projetual; é quando as informações levantadas e analisadas começam a ser transformadas em estruturas que darão base à programação do sistema e à nova interface. Essa fase começa com uma visão geral, na construção do mapa do site, passa pelo desenho de conteúdo e função, e, em seguida, parte para detalhamentos mais específicos no fluxo das tarefas e nos caminhos de navegação. Essas três etapas têm base na Engenharia de Software (Pressman, 2002) e na Experiência do Usuário (Garrett, 2003). Por fim, a validação dos gráficos mediante consulta com a equipe de desenvolvimento é uma etapa criada a partir da proposta de avaliação do que está sendo feito durante o processo, advinda do Design de Interação (Preece, Rogers e Sharp, 2005). 
Conforme Kalbach (2009) o mapa do site demonstra os relacionamentos entre conteúdo e funcionalidade na arquitetura de um site. Em uma representação visual, captura o conceito, a estrutura da informação e o esquema da organização do site.

\section{Desenho de conteúdo ou função}

O desenho de conteúdo trata-se da produção ou reunião de todos os elementos que farão parte de cada uma das páginas, como: textos, gráficos e animações. Da mesma forma, o desenho de função descreve quais funções estarão disponíveis nas páginas do sistema (Pressman, 2002).

\section{Fluxo de tarefa e caminhos de navegação}

O fluxo de tarefa é uma representação gráfica que mostra como se dá a execução das atividades em um sistema. Dessa forma, contribui para a elaboração de respostas do sistema bem como para o design da interação. O caminho de navegação, por sua vez, demonstra a navegação de forma mais completa que o mapa do site, trazendo também as ligações secundárias. Kalbach (2009) afirma que no mapa do site a apresentação é de cima para baixo, enquanto o caminho de navegação atravessa toda a estrutura conforme exista necessidade de unir conteúdos relacionados.

\section{Validação da configuração}

A fase de configuração encerra com a validação dos gráficos pelos desenvolvedores e responsáveis pelo projeto. Kalbach (2009) considera que a apresentação do mapa para a equipe de desenvolvimento é importante para que sejam evitados problemas de interpretação.

\section{Fase (d) Esboço}

Acessibilidade, usabilidade e ergonomia envolvem preocupações que estão presentes em todas as fases do projeto, mas que se tornam evidentes na fase do esboço. Esta etapa se destina à composição da página, visando a compreensão das informações e a utilização das funções por parte do usuário. Trata-se de estabelecer as relações entre os elementos gráficos e de demonstrar a hierarquia da informação. O design da interface é aqui definido através da malha construtiva, da malha estrutural e do design de navegação. O embasamento para essas etapas vem dos Elementos da Experiência do Usuário (Garrett, 2003). Por fim, a validação do esboço tem base na validação do desenho de interface proposta na Engenharia de Software (Pressman, 2002).

\section{Malha construtiva}

A malha ou grade de construção é um sistema modular que serve de base para o desenho. Samara (2007, p.24) define grade como um "conjunto específico de relações de alinhamento que funcionam como guias para a distribuição dos elementos num formato". Garrett (2003) afirma que essa técnica trazida do impresso pode assegurar uniformidade e consistência à interface Web.

\section{Malha estrutural}

A malha estrutural ou wireframe definirá a distribuição espacial dos elementos da interface levando em conta a relevância de cada informação. Kalbach (2009) descreve wireframe como o esboço preliminar das páginas que mostra o esqueleto do sistema de navegação ainda sem o design visual.

\section{Design da navegação}

O design da navegação define a forma como o usuário se movimenta no sistema, com a localização e os tipos de links (texto, ícones, botões ou metáforas gráficas). Conforme Garrett (2003) o design da navegação refere-se ao design dos elementos da tela que permitem a movimentação do usuário através da arquitetura da informação.

\section{Validação do esboço}


Antes de dar prosseguimento ao refino do projeto o esboço deve obter a devida validação em apresentação aos pesquisadores, desenvolvedores e responsáveis pelo projeto.

\section{Fase (e) Refino}

$\mathrm{Na}$ fase do refino, a aparência final da interface revela-se através do design visual. Conforme Garrett (2003) o design visual interfere não apenas na estética da interface, mas tem influência também na funcionalidade, na estratégia de posicionamento de marca e na legibilidade de textos e imagens. A definição da identidade visual garante personalidade ao sistema, forma um conceito visual e dá base para o restante do tratamento gráfico da página. As etapas de desenho da identidade visual e de tratamento gráfico da interface advém da abordagem da Experiência do Usuário (Garrett, 2003), ao passo que as duas últimas, validação do refino e identificação de possíveis aperfeiçoamentos, têm base na Engenharia de Software (Pressman, 2002).

\section{Identidade visual}

As pesquisa referentes à identidade visual e ao painel semântico, fornecem, nesse momento, orientação e dão o direcionamento na definição da paleta de cores, das famílias de fontes, das formas e dos elementos gráficos que serão empregados na nova marca e comporão o leiaute da interface.

\section{Tratamento gráfico da interface}

Trata-se do design visual, quando os elementos gráficos, textos e componentes da navegação recebem tratamento de acordo com princípios de design gráfico, tais como: agrupamento, equilíbrio, contraste, proporções e legibilidade (Garrett, 2003). Nessa etapa, os ícones e menus são projetados e é finalizada a composição e aparência da interface.

\section{Validação do refino}

A etapa final do refino prevê a apresentação do projeto gráfico para os responsáveis pela pesquisa do HyperCAL online para identificação de possíveis ajustes e validação do projeto.

\section{Identificação de possíveis aperfeiçoamentos}

Mediante a construção do protótipo e finalizada a pesquisa, podem ser identificados possíveis aperfeiçoamentos e formuladas proposições de melhorias.

O Quadro 2 apresenta graficamente as 5 fases e as 25 etapas da metodologia Hypercal.

\begin{tabular}{|c|c|}
\hline Fase & Atividade \\
\hline Percepção & $\begin{array}{l}\text { - Levantamentos de informações } \\
\text { - Identificação dos objetivos do projeto } \\
\text { - Identificação dos recursos disponíveis (humanos, financeiros e tecnológicos) } \\
\text { - Identificação dos prazos } \\
\text { - Análises } \\
\text { - Denotativa e Conotativa } \\
\text { - Investigação de tendências } \\
\text { - Diacrônica e Sincrônica } \\
\text { - Identificação dos requisitos do usuário } \\
\text { - Catalogação das informações obtidas }\end{array}$ \\
\hline Alvo & - Investigação de oportunidades para inovação \\
\hline
\end{tabular}




\begin{tabular}{|c|c|}
\hline & $\begin{array}{l}\text { - Desdobramento da função qualidade - QFD } \\
\text { - Análise de concorrente e/ou similares } \\
\text { • Investigação de identidade visual } \\
\text { - Questionário de perfil de identidade visual } \\
\text { - Diferencial semântico } \\
\text { - Montagem dos condicionantes } \\
\text { - Listagem de projetações } \\
\text { - Análise dos dados obtidos, definição das metas e formulação do conceito. } \\
\text { - Definição de tarefas e prazos }\end{array}$ \\
\hline Configuração & $\begin{array}{l}\text { - Mapa do site } \\
\text { - Desenho de conteúdo ou função } \\
\text { - Fluxos de tarefa e caminhos de navegação } \\
\text { - Validação da configuração }\end{array}$ \\
\hline Esboço & $\begin{array}{l}\text { - Malha construtiva, módulos } \\
\text { - Malha estrutural, wireframes } \\
\text { - Design de navegação } \\
\text { - Validação do esboço }\end{array}$ \\
\hline Refino & $\begin{array}{l}\text { - Identidade dígito-virtual } \\
\text { - Tratamento gráfico da interface } \\
\text { - Elementos gráficos, paleta de cores, estilo de texto, menus, ícones, interface das } \\
\text { funções (respostas do sistema) } \\
\text { - Validação do refino } \\
\text { - Identificação de possíveis aperfeiçoamentos }\end{array}$ \\
\hline
\end{tabular}

\section{Representação circular da metodologia}

Outra representação para esta metodologia pode ser vista na Figura 1. Esse modelo circular demonstra as características específicas de cada fase de processo. O círculo azul indica que a preocupação com a ergonomia cognitiva, usabilidade e acessibilidade deve estar presente em todas as fases. O semicírculo verde mostra que a arquitetura da informação é abrange quase todas as etapas. A parte amarela distingue as duas fases de diagramação e composição, respectivamente Esboço e Refino. Enquanto isso, o laranja destaca a Configuração e o Esboço como fases de sinalização e navegação.

A fase da Percepção, por ser uma etapa de coleta e análise de dados é dita analítica, sendo que as informações levantadas podem ser apresentadas em forma de imagens, desenhos ou palavras. A fase Alvo é destinada a organização e estruturação das informações obtidas e pode também ser representada com textos ou desenhos. As fases Configuração e Esboço mantêm as características organizacional e estrutural e tornam a ser analíticas em seus detalhes específicos. As representações na Configuração podem ser desenhísticas ou linguísticas, enquanto no Esboço são predominantemente desenhísticas. A fase final, Refino, é desenhística, trazendo o design visual da interface. Mais ao centro, são expostas as principais ações de cada fase, já detalhadas acima, neste artigo. 
Figura 1: Metodologia Hypercal

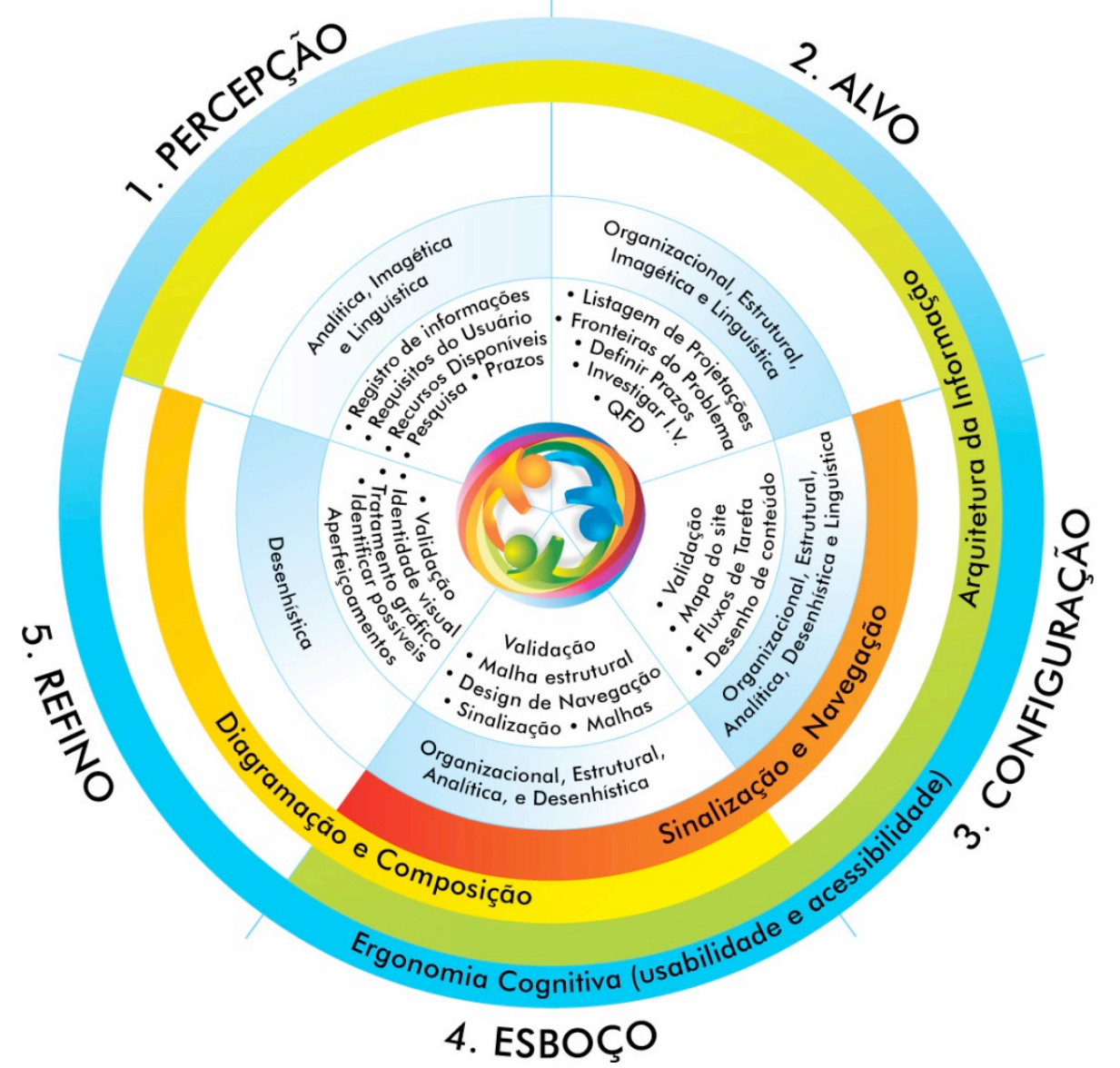

\section{Considerações finais}

Para validação, a metodologia foi apilcada no projeto de interface do HyperCAL online - módulo do professor (Passos, 2010). O estudo desenvolvido permite observar que o design de interface deve consistir em um processo que se inicia na definição das necessidades do usuário e objetivos do site; passa pela escolha de funcionalidades; pelo design de interação; segue com a arquitetura da informação e com o design dos elementos da interface; e culmina em um tratamento gráfico especializado em design visual para superfície web (Garrett, 2003). Ressalta-se que, para manterse a qualidade em todas as etapas do processo, é importante que sejam adotadas técnicas profissionais de design de produto (Baxter, 1998). Dessa forma, propicia-se que as questões visuais e de usabilidade, imprescindíveis a uma experiência de usuário satisfatória, encontrem amparo em técnicas que garantem precisão e qualidade ao processo. O HyperCAL online encontra-se, atualmente, em fase de protótipo. Novas publicações poderão relatar os resultados da interação entre os usuário e a nova interface desenvolvida seguindo a metodologia apresentada neste artigo.

\section{Referências}

BAXTER, M., 1998. Projeto de Produto: guia prático para o design de novos produtos / Mike Baxter; tradução Itiro lida. $2^{a}$ ed. ver. São Paulo: Edgard Blücher.

GARRETT, J.J., 2003. The elements of user experience: user centered design for the web. New York/Berkeley: Aiga/New Riders.

KALBACH, J., 2009. Design de navegação Web. Porto Alegre: Bookman. 
MENDES, R. M., 2009. Avaliação da interface de desenvolvimento de materiais educacionais digitais no ambiente HyperCAL online. Dissertação submetida ao Programa de Pós-Graduação em Design da UFRGS.

MEURER, H., 2004. Projetação de Sistemas de Administração de Sítios Virtuais: O Atualizador / por Heli Meurer - Santa Maria.

NIELSEN, J. Ten Usability Heuristics. 2005. Disponível em:

<http://www.useit.com/papers/heuristic/heuristic_list.html>. Acesso em dezembro de 2008.

NORMAN, D. A., 2002. The design of everyday things. New York: Basic Book.

PASSOS, J. E., 2010. Metodologia para o design de interface de ambiente virtual centrado no usuário. Dissertação (Mestrado), Universidade Federal do Rio Grande do Sul.

POWELL, T. A. JONES, D. L. CUTTS, D.C., 1998. Web site engineering: beyond Web page design. Upper Saddle River: Prentice-Hall.

PREECE, J. ROGERS, Y. SHARP, H., 2005. Design de Interação: além da interação homemcomputador. Porto Alegre: Bookman.

PRESSMAN, R. S., 2002. Ingeniería del Software: Un enfoque prático. Madrid: Concepción Fernández Madrid.

SAMARA, T., 2007. Grid: construção e desconstrução. Tradução de Denise Bottmann. São Paulo: Cosac Naify.

SAWAYA, M. R., 1999. Dicionário de informática e internet: inglês - português. São Paulo: Nobel.

SILVA, T. L. K., 2005. Produção flexível de materiais educacionais personalizados: o caso da geometria descritiva. Florianópolis: Programa de Pós-Graduação em Engenharia de Produção PPGEP/UFSC (Tese de Doutorado).

\section{Sobre os autores}

Jaire Ederson Passos, mestre, Universidade Federal do Rio Grande do Sul (UFRGS), Centro Universitário Ritter dos Reis (UNIRITTER), atua como professor nos cursos de Design Visual e de Design de Produto nas disciplinas de Projeto Editorial e Hipermídia. Pesquisa design de interface, arquitetura da informação, processo de desenvolvimento de produto e planejamento visual.

<jairepassos@gmail.com>

Tânia Luisa Koltermann da Silva, doutora, Universidade Federal do Rio Grande do Sul, professora do Departamento de Design e Expressão Gráfica da Faculdade de Arquitetura e do Programa de Pós-Graduação em Design. Atua principalmente nos seguintes temas: geometria descritiva, objetos de aprendizagem, aprendizagem, ensino, hipermídia adaptativa, projeto de produto, tecnologia assistiva e metodologia de pesquisa.

<tania.koltermann@ufrgs.br>

[Artigo recebido em dezembro de 2012, aprovado em dezembro de 2012] 